\title{
USO E APROPRIAÇÃO DA PRAÇA NOSSA SENHORA DA CONCEIÇÃO: UMA VISÃO DA SUSTENTABILIDADE AMBIENTAL DO ESPAÇO PÚBLICO DE CORRENTES-PE
}

\author{
Ana Maria Severo Chaves $^{1}$
}

\section{Maria Betânia Moreira Amador²}

Resumo: As praças na atualidade nem sempre são vistas como espaço público de lazer, a ela são atribuídos diversos adjetivos, referentes a seu uso e apropriação. No caso das praças das grandes cidades, dependendo da localização, elas podem ser um espaço livre abandonado à marginalidade e representam um ambiente hostil e indesejado. Em função disso, principalmente as famílias, procuram suprir para os filhos espaços livres e de lazer dentro dos condomínios, situação visível em cidades de médio e grande porte. No caso de pequenas cidades, embora também haja situação semelhante, o grau de percepção desses espaços ainda não oferece tanta periculosidade e, por outro lado, esses espaços livres geralmente são apropriados por pequenos comércios, feiras e pessoas que os utilizam em seus momentos de lazer. Porém toda praça ou qualquer espaço urbano arborizado é um conjunto sistêmico que contribui para a sustentabilidade ambiental das cidades. Objetiva-se averiguar os modos de uso e apropriação do principal espaço público de Correntes-PE e diagnosticar a sua contribuição para sustentabilidade ambiental. A metodologia é voltada à percepção com registros fotográficos e entrevistas abertas feitas com a população que usa ou se apropria da Praça Nossa Senhora da Conceição. Chegando-se à confirmação de que são poucos frequentadores desses espaços livres que percebem mais de três funções ou benefícios oferecidos pela praça, bem como mostram alguma preocupação com os cuidados e manutenção desse ambiente, mas que é um patrimônio da população, onde a mesma também deve contribuir para sua integridade ambiental, estética e recreativa.

Palavras chaves: Praça Nossa Senhora da Conceição. Sustentabilidade Urbana. Percepção.

\footnotetext{
${ }^{1}$ Graduanda de L. em Geografia pela UPE-Campus Garanhuns. E-mail: aninhasevero07@hotmail.com

${ }^{2}$ Pro.. ${ }^{a}$ Adjunta da UPE-Campus Garanhuns. E-mail: betaniaamador@yahoo.com.br
} 


\section{INTRODUÇÃO}

Com o desenvolvimento dos centros urbanos, devido a fatores econômicos e sociais, a presença de espaços livres destinados à arborização e lazer é um fator que remete a um dilema da sustentabilidade, cada vez mais estudado no presente, devido a sua função diante de um espaço marcado por edificações que sofrem diariamente com a poluição visual, sonora e ambiental, provenientes das atividades antrópicas no meio ambiente das cidades.

O espaço urbano é um cenário de desenvolvimento econômico que por vários motivos deixa a desejar no que se refere a ambientes naturais, os quais desenvolvem funções ambientais benéficas à população urbana. Onde os ambientes arborizados proporcionam lazer e bem estar à população e refletem relevantes benefícios ao meio urbano como um todo e a própria natureza, por oferecerem um espaço propicio a presença da micro fauna e uma área livre de edificações, além de contribuir para redução da poluição nas cidades impulsionando uma melhor qualidade de vida.

Entre os espaços livres das cidades, estão às praças públicas, que podem ser arborizadas ou não. As praças sem a presença de elementos naturais seja a arborização ou vegetação, são destinadas a uma atividade específica como praça de eventos ou praça de alimentação, já as praças arborizadas apresentam diversas funcionalidades a população, contribuindo para conservação da natureza, a qual foi destruída para construção das cidades e, ao mesmo tempo, necessária para o bom desenvolvimento do ambiente urbano.

A praça é uma construção espacial para manutenção ambiental com diversos modos de uso e apropriação do seu espaço. De acordo com Milton Santos, "O espaço é formado por um conjunto indissociável, solidário e também contraditório, de sistemas de objetos e sistemas de ações, não considerados isoladamente, mas como o quadro único no qual a história se dá." (SANTOS, 1997, p. 51). E a praça é um bom exemplo de espaço sistêmico de objetos e ações que se reflete na contradição ao meio ambiente das cidades.

Assim, a praça é percebida como a permanência da natureza nos centros urbanos e é um lugar de diversos usos que proporcionam lazer e bem estar para a população. 
Nela também é desenvolvido modos de apropriação, com determinados fins como o econômico ou, até mesmo a estética que, indiretamente, influencia a especulação imobiliária no entorno. Sendo que, no caso da Praça Nossa Senhora da Conceição objeto de estudo para o presente trabalho, localizada no Município das Correntes-PE (figura 1), pode-se perceber esses diversos usos e apropriações, que mudam em curto período tempo, dependendo do dia da semana, as formas de apropriação e uso econômico pela população.

Mapa de Localização de Correntes-PE

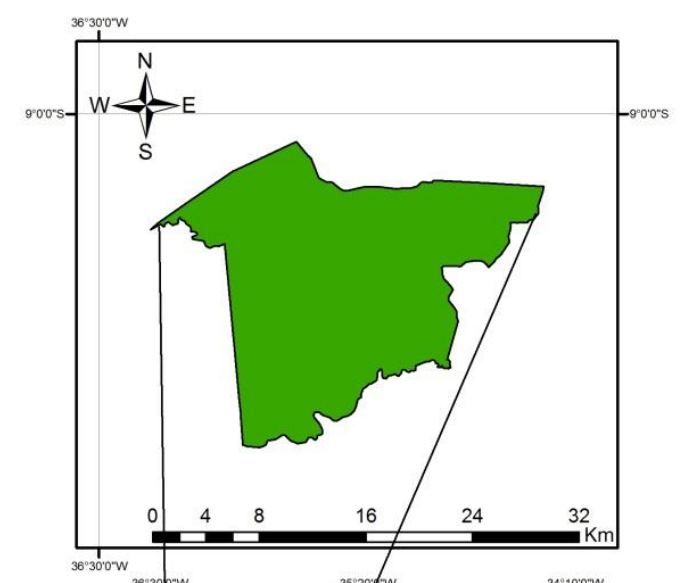

Legenda

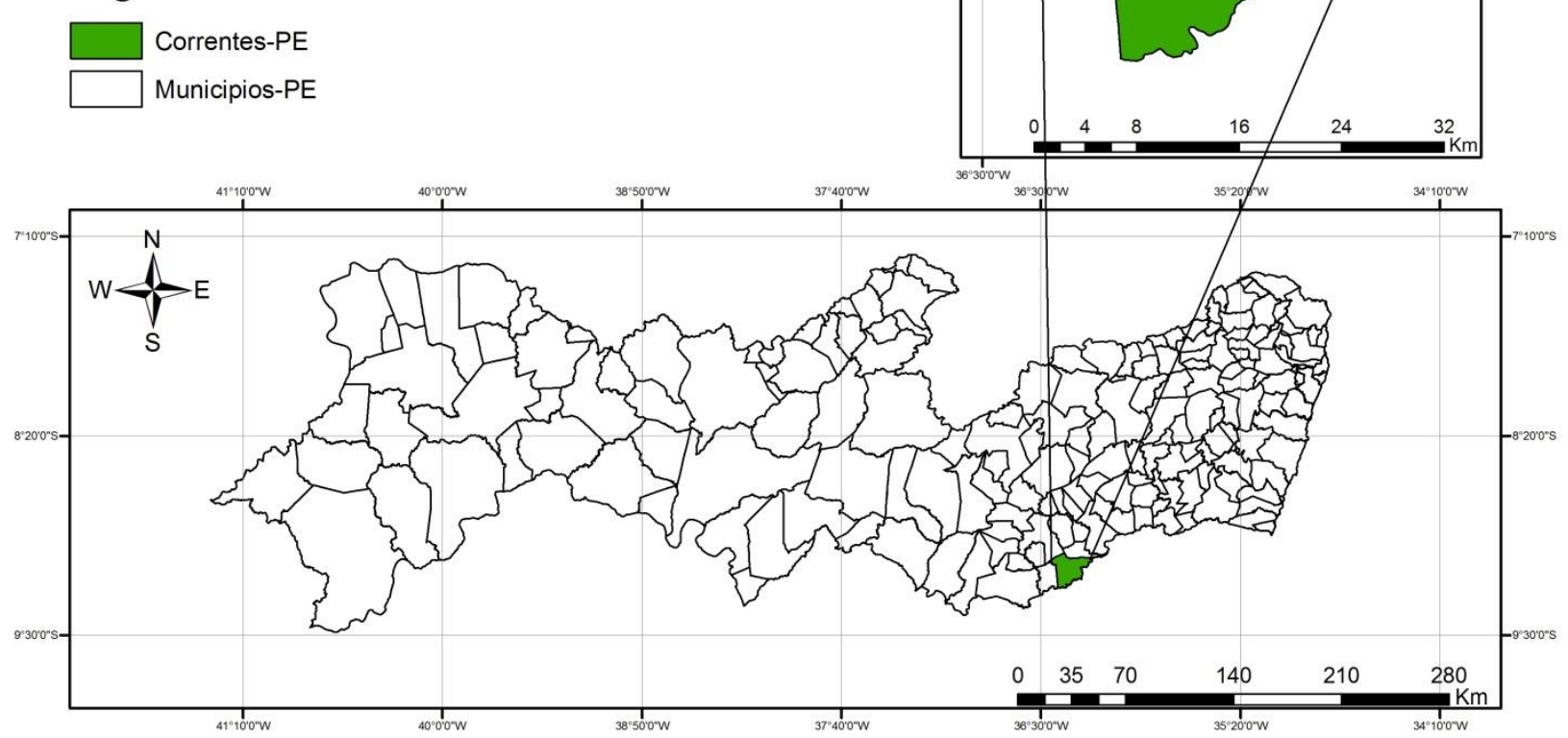

Figura 1: Mapa da localização de Correntes-PE. Fonte: Chaves 2013.

Assim, para a realização do presente trabalho, o qual representa parte da pesquisa realizada sobre o projeto O VERDE DAS PRAÇAS E CANTEIROS CENTRAIS NA PERSPECTIVA DA ORGANIZAÇÃO DO ESPAÇO NUMA ABORDAGEM SISTÊMICA DA PAISAGEM AGRESTE DE CORRENTES-PE integrante dos trabalhos no Grupo de 
Estudos Sistêmicos do SemiÁrido do Nordeste - GESSANE, que entre as pesquisas desenvolvidas, estão estudos sobre o verde urbano e rural do agreste de Pernambuco.

A pesquisa desenvolvida sobre o uso e apropriação da Praça Nossa Senhora da Conceição de Correntes-PE que envolve o centro, o comercio e a principal localização da cidade, teve como objetivos averiguar os modos de uso e apropriação do principal espaço público de Correntes-PE, diagnosticar a contribuição desse espaço arborizado para sustentabilidade ambiental do município e perceber como a população se relaciona com o espaço sistêmico da praça.

Em decorrência, a praça entendida como uma representação de um espaço público e que se encontra disponível para toda população residente ou visitante do município, também é introjetada no imaginário popular como a permanência da natureza na cidade. $\mathrm{E}$, diferente de algumas cidades, que por algum motivo, abandona as praças deixando-as associadas a um ambiente hostil ao uso da população, a Praça estudada em Correntes$\mathrm{PE}$, ao contrário, é um espaço bastante usado e apropriado, embora poucos dos seus frequentadores entendam suas contribuições para sustentabilidade ambiental da cidade.

\section{2. ÁREAS VERDES URBANAS: UMA CONTEXTUALIZAÇÃO DA PRAÇA NOSSA SENHORA DA CONCEIÇÃO}

Para introduzir a praça em tela no presente trabalho, faz-se necessário uma contextualização sobre o que podemos entender sobre áreas verdes. Logo, de acordo com alguns autores, há o entendimento que as áreas verdes urbanas estão presentes nos espaços livres de construções que, segundo CARNEIRO; MESQUITA (2000), o espaço urbano é composto por espaços edificados e espaços livres de construções onde:

Os espaços edificados são áreas ocupadas de maneira significativamente densa pelas construções que atendem as atividades do meio urbano: de uso residencial, comercial, industrial, de serviços de educação, saúde, educação, entre outras que, geralmente em proporção direta, em número e grau de complexidade, ao tamanho e importância do aglomerado populacional. (CARNEIRO; MESQUITA, 2000, p. 24).

Já os espaços livres de construções, no contexto da estrutura urbana, são áreas parcialmente edificadas com nula ou mínima proporção de elementos construídos ou de 
vegetação, como por exemplo, avenidas, ruas, vielas, entre outros. Ou com presença de vegetação, como por exemplo, praças, parques, jardins, canteiros, etc. que tem como funções no espaço urbano a recreação, circulação, composição paisagística, estética e de equilíbrio ambiental.

Assim, a cidade é formada por diversos espaços que são modificados apropriados, recriados e, tornam-se propícios a criação de novos espaços com novas funções em um conjunto sistêmico de interação e relações que variam de acordo com a percepção do observador. Dessa forma arma-se a espiralidade sempre presente e alimentada pelos fenômenos e contradições, cernes do pensamento sistêmico e que favorecem um novo olhar para a pesquisa que, segundo Amador (2009),

\begin{abstract}
ao se ampliar o foco da observação, está-se tentando se aproximar da complexidade da questão. Pode-se perceber em que circunstâncias o fenômeno acontece, ver-se-á relações intra-sistêmicas e inter-sistêmicas. É possível perceber não mais um fenômeno, mas uma teia de fenômenos recursivamente interligados e, portanto, ter-se-á diante de si a complexidade do sistema. Assim sendo, pode-se considerar o pensamento sistêmico como um novo paradigma da Ciência, trata-se de um novo ou renovado modo de pensar". (AMADOR, 2009, p. $69)$.
\end{abstract}

Os espaços na cidade são entrelaçados em uma malha complexa, onde os espaços construídos se combinam com os espaços livres e se integram fazendo da cidade um lugar mais harmonioso devido à contradição da permanência da natureza, onde a mesma foi destruída para dar lugar à cidade. Assim, Amador (2011) salienta que "a Geografia apoiada em princípios sistêmicos, pode ser aplicada e contribuir no planejamento do território a buscar conexões entre os componentes da natureza e da socioeconomia" (AMADOR, 2011, p.113).

Por sua vez, Schutzer (2012), reforça a ideia da composição da cidade, com ênfase no estudo com suporte geógrafo, afirmando que, "Toda cidade é composta por volumes construídos e espaços livres, que estão dispostos em diversos matizes sobre um suporte geográfico" (SCHUTZER, 2012, p. 139). Pode-se dizer assim, que a ciência geográfica permite uma melhor compreensão sobre as relações, interações e construções espaciais que se dá no território de forma sistêmica. Nesse contento, então, as áreas verdes são assimiladas como uma forma de contradição na cidade e representam um ambiente 
puramente sistêmico graças a sua diversidade de uso e apropriação de forma interacional, visto que em um espaço livre não há acontecimentos isolados.

Diante das colocações apresentadas, as áreas verdes são espaços de contradição que torna a cidade um ambiente mais harmonioso. São localizadas em espaços livres de construções sujeitas a relações sistêmicas do urbano, onde proporciona benefícios a sociedade e tem, através pesquisas no âmbito geográfico, um melhor entendimento das relações homem e meio ambiente/urbano. Nas contradições dessa relação, as ações antrópicas transformam, constantemente, a superfície terrestre na busca de um espaço mais sustentável e adequado ao desenvolvimento das relações socias, econômicas e ambientais.

Em sequência, no trabalho de Benini e Martin (2011) sobre áreas verdes temos os trabalhos de Daltoé, Cattoni, Loch que determinam seis categorias de áreas verdes, quais sejam:

\begin{abstract}
Áreas verdes do sistema viário - Predominam vegetações de porte arbustivo e herbáceo. Representam os canteiros, trevos e rotatórias, associados ou não às redes de transmissão de energia. Apresentam-se com valor ecológico variando de baixo a médio e valor cênico médio. Por não possuírem nenhuma estrutura que possa atender às necessidades da população, possuem um baixo valor social.

Áreas verdes de uso particular - Predominam vegetações de porte arbóreo. Neste grupo estão situadas as áreas verdes que se apresentam em domínios de uso habitacional particular. São áreas inacessíveis para uso público devido à ausência de acessos e infra-estruturas. Seu valor ecológico é médio, enquanto o cênico e de conforto apresenta-se variando de médio a alto. Devido à impossibilidade de uso direto pelo público seu valor social varia entre médio e baixo.

Áreas verdes residuais - Áreas herbáceo-arbustivas com ou sem cobertura arbórea. Em geral, representam as áreas verdes em loteamentos recentes ou em fase de implantação. Não se enquadram na classificação quanto aos valores cênicos, sociais e ecológicos devido à instabilidade da situação de uso atual.

Áreas verdes institucionais - Possuem distintas configurações, representadas pelos jardins, áreas verdes de uso institucional, campos de futebol etc. Seu valor cênico é alto e seu valor ecológico e social é médio, devido à restrição de alguns equipamentos para uso da coletividade.

Áreas verdes públicas e/ou de uso coletivo - Nesse grupo enquadram-se as áreas verdes de composição mista com arborização significativa (espécies exóticas e nativas). Compreendem as praças, parques e bosques urbanos, assim como áreas arborizadas dentro dos complexos históricos. Possuem alto valor ecológico, cênico e social.

Áreas livres não arborizadas (vazios urbanos) - Compreendem as coberturas herbáceo-arbustivas (predominantemente gramíneas). Os lotes vazios, característicos principalmente em áreas urbanas de consolidação recente, caracterizam este grupo. (DALTOÉ; CATTONI; LOCH, 2004, p. 3-4, organização é negrito nosso) (DALTOÉ; CATTONI; LOCH apud BENINI; MARTIN 2011, p. 66).
\end{abstract}


Verifica-se, então, que as áreas verdes estão presentes em todo complexo urbano, seja nas locais públicos ou particulares, com uso específico ou uso coletivo, função estética ou de lazer ou para apropriação e locação de uma determinada atividade. As autoras, nesse mesmo trabalho sobre praça, citam que "a praça assume também a função de embelezamento da cidade, ao sediar prédios públicos, com proeminente arquitetura oferecendo um espaço convidativo ao lazer e às atividades cívico-religiosas" (BENINI; MARTIN 2011, p. 69), e é fato que toda praça destaca-se das demais áreas verdes, por ela designar um nome homenageando, normalmente, pessoas ilustres no âmbito da sociedade (prefeito, sindicalista, professor, médico, padre, santos entre outros.)

No trabalho de Santos (2001), toda vegetação urbana deve considerada como área verde, bem como todo complexo arbóreo presente na cidade segundo o autor, deve ser considerado área verde.

Para nós toda a vegetação existente na cidade deve ser considerada como área verde, inclusive as árvores de porte que estão nos quintais, ou seja, em áreas particulares (...), pois também estão sob fiscalização do Poder Público, por força do contexto jurídico atual que as protege. Em suma, toda vegetação ou árvore isolada, quer seja ela pública ou particular, ou de qualquer forma de disposição que exista na cidade, constitui a "massa verde urbana", por consequência a sua área verde. (SANTOS, 2001, p.1).

No caso da Praça Nossa Senhora da Conceição de Correntes-PE (Figura 2), correspondendo a uma área verde em um espaço livre de construção, com a finalidade de lazer, estética, circulação, comercial e ambiental. Ela é usada diariamente por seus habitantes e visitantes, enquanto a apropriação sobre esse espaço público tem no próprio significado da palavra apropriação a reflexão da ação do homem sobre a praça que, segundo o dicionário online de português é, "Ato de apropriar ou apropriar-se. Acomodação, adaptação" (DICIONÁRIO ONLINE DE PORTUGUÊS, disponível em: $<$ http://www.dicio.com.br/>, acesso em 15 de agosto de 2013). 


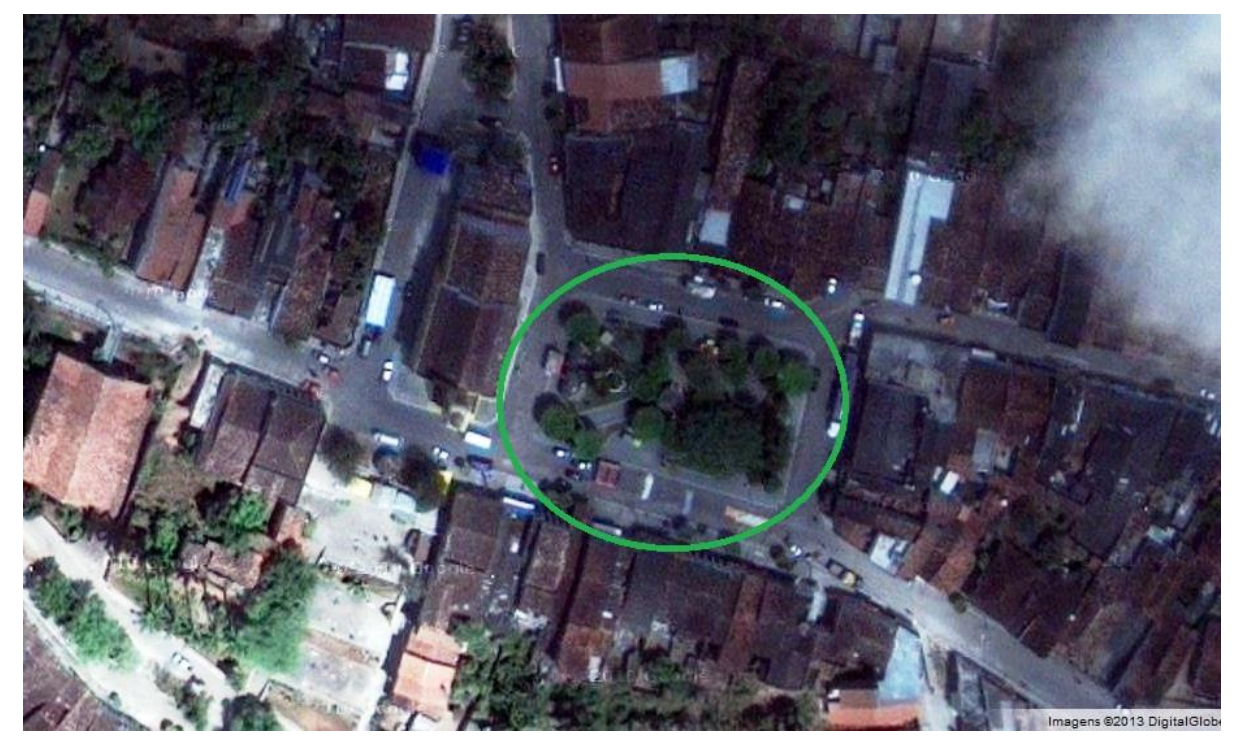

Figura 2: imagem da praça N. Senhora da Conceição- Correntes-PE. Fonte: https://maps.google.com/

Na figura 2, visualiza-se a arborização da praça, parte de sua área de circulação e algumas pequenas construções que significam a apropriação desse espaço arborizado por parte de algumas pessoas que se apropriam com finalidade econômica. É o exemplo da pequena sorveteria, bar e barracas de salgadinhos e doces.

\section{PRAÇA NOSSO SENHORA DA CONCEIÇÃO, USOS E APROPRIAÇÕES DO ESPAÇO PÚBLICO}

A Praça Nossa Senhora da Conceição é um espaço construído que, segundo Dardel (2011), "O espaço construído coloca em cheque o alcance do olhar, apaga e submerge o desenho natural dos lugares" (DARDEL, 2011, p.29). Esse espaço tem dentro de si, sua principal importância, à construção do habitat do homem. A construção de um ambiente harmônico para as vidas e relações sociais do homem com a terra.

E a praça como espaço de contradição construído para proporcionar um ambiente urbano com mais qualidade, é um lugar de relações sociais sistêmicas, permitindo que a interação e inter-relação das vidas nela presentes, se deem harmoniosamente entre os elementos artificiais e naturais, através dos modos de apropriação e uso da mesma.

Ao falar de apropriação de um espaço público como a praça, o trabalho de Serpa (2007), faz referência ao espaço público como área susceptível a apropriação do capital e 
a coletividade cultural, onde, "no espaço público da cidade contemporânea, o "capital escolar" e os modos de consumo são os elementos determinantes das identidades sociais. (...) diferença e desigualdade articulam-se no processo de apropriação espacial, definindo uma acessibilidade que é, sobretudo, simbólica”. (SERPA, 2007, p.20).

O autor, ainda, cita os modos de privatização dos espaços públicos pelos diferentes grupos urbanos, os quais criam uma identidade através da apropriação do lugar, que pode variar de acordo com os grupos culturais, econômicos e sociais que atuam no processo de territorialização do espaço público.

Vendo essa abordagem verifica-se que, a Praça estudada não apresenta essa categoria de territorialização, ela é um espaço frequentado por toda a população Correntense como lugar de lazer, circulação e comercial que muda de acordo com os dias da semana, onde o modo de apropriação varia devido às atividades desenvolvidas no próprio município.

Assim, temos como modos de apropriação da praça a finalidade econômica: a presença de uma sorveteria, um bar e algumas barracas de salgadinhos e doces; apropriação de elementos contidos na própria praça com finalidade estética e de lazer: um chafariz e um caramanchão no centro da praça (Figura 3).

\section{Modos de Apropriação da Praça Nossa Senhora da Conceição}

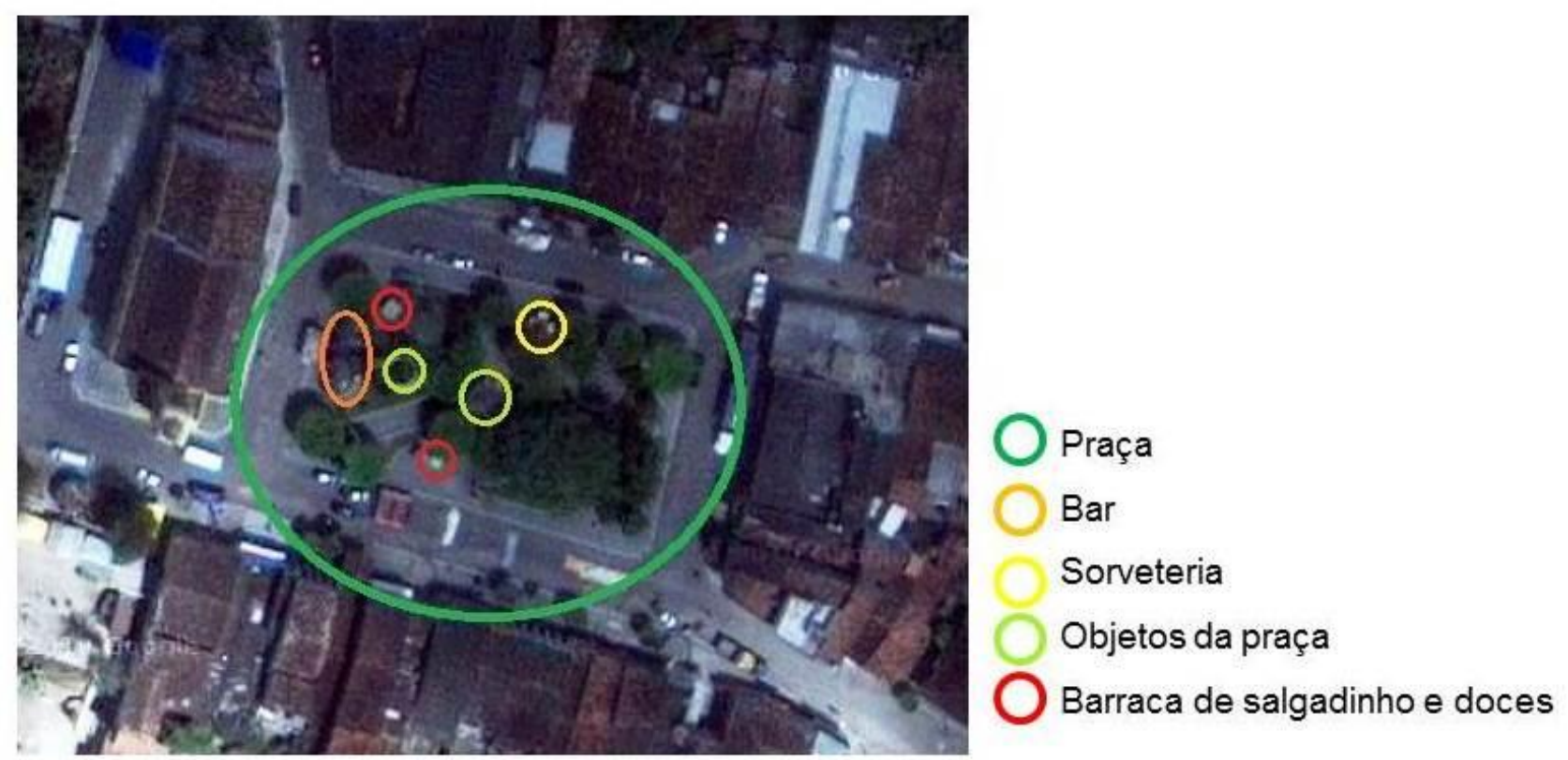

Figura 3: Modos de apropriação da Praça N. Sr. 므 da Conceição Correntes-PE. Adaptação: Chaves 2013. 
A figura 3 possibilita visualizar a disposição desses equipamentos mencionados na praça, ou seja, um bar que é utilizado na maioria das vezes por homens ao fim da tarde; a sorveteria que é frequentada por boa parte da população que costumam ir à praça, principalmente nos dias de verão; as barracas de doces e salgados, onde os principais consumidores são as crianças e adolescentes, sendo que a imagem acima só permite visualizar duas barracas, ressaltando que são quatro barracas do mesmo tipo.

Apesar dessa diversidade de gêneros alimentícios que gera certa quantidade de lixo, por causa dos papeis e balas, biscoitos, salgadinhos e pazinhas de sorvetes, não existe lixeiro na praça. Assim, algumas barracas colocam seu próprio lixeiro. Mas, mesmo assim, a população por falta de educação ambiental acaba jogando o lixo no chão, o que deixa a praça muitas vezes cheia de lixo, principalmente dia de sábado, dia escolhido pelo município para realização da feira livre.

As principais utilizações da praça N. Senhora da Conceição são: circulação devido à localização da mesma, a qual se encontra no ponto central do município; lazer (Figura 4) quando a população se reúne para conversar, brincar (crianças e adolescentes), jogar cartas ou dominó, andar de bicicleta, namorar entre outros lazeres; consumo (Figura 5), tomar sorvete, comprar doces e salgadinhos e tomar uma cachaça com os amigos (os adultos); ou simplesmente usam esse espaço para aproveitar um ambiente agradável na cidade desfrutando de elementos naturais e artificiais e dos inúmeros benefícios da arborização presente.
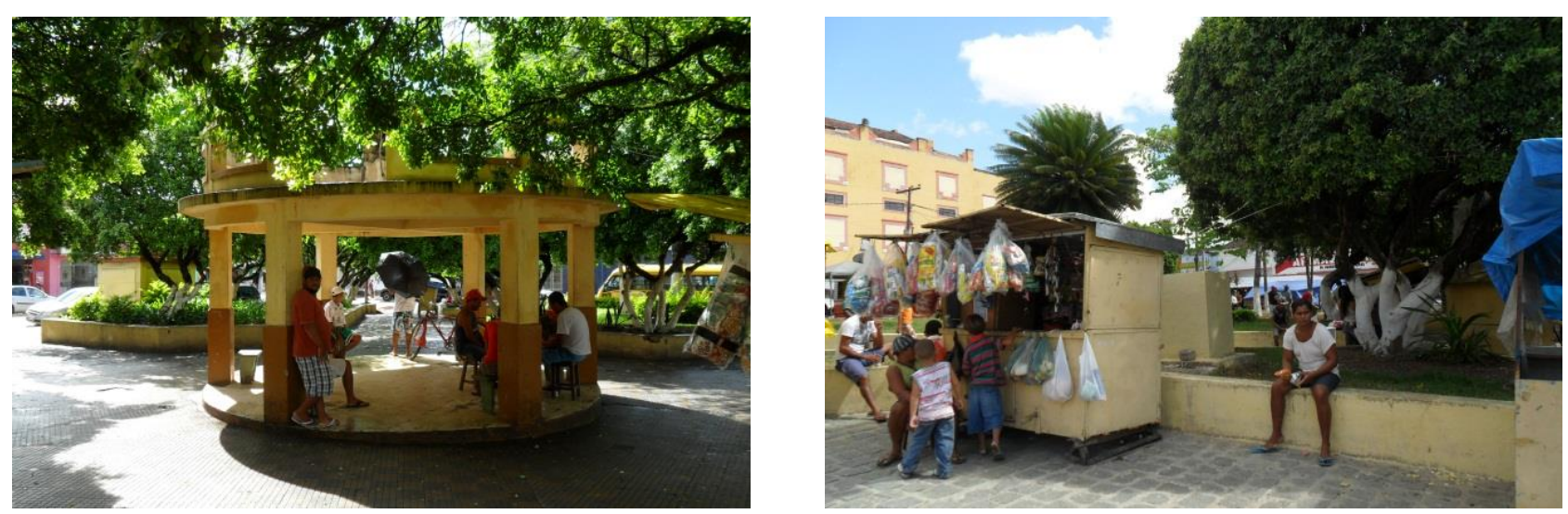

Figuras 4-5atividades cotidianas na praça N. Sr. ${ }^{\underline{a}}$ da Conceição em Correntes-PE. Fonte: Chaves 2013. 
Esses modos de uso da Praça Nossa Senhora da Conceição são dominantes, porém nos fins de semana a praça apresenta maior concentração de pessoas em determinados horários.

\section{1 A Praça Nossa Senhora da Conceição aos Sábados e Domingos}

Culturalmente o sábado é o dia de feira livre do município das Correntes-PE, e como na maioria das cidades pequenas a feira se realiza no centro da cidade. Esse local de Feira corresponde à Praça Nossa Senhora da Conceição e seus arredores, estendendo-se por ruas próximas.

Destacando-se que a praça na sua história e desenvolvimento, surgiu devido a apropriação de um terreno pertencente à Igreja Nossa Senhora da Conceição para realização da feira livre e, durante diferentes gestões, o terreno começou a ser estruturado ao poucos para melhorar o local escolhido para o comércio semanal. Depois devido ao quantitativo de frequentadores, teve-se a necessidade de ser construir um espaço agradável a população, e desenvolvimento do comércio da cidade. Desenvolveuse assim, a Praça Nossa Senhora da Conceição.

Logo, nos sábados, a cidade recebe grande parte da população rural para fazer a feira de suas casas. A praça fica com um enorme fluxo de pessoas que, quase sempre, reserva um tempo para conversar com um amigo embaixo das árvores, tomar um sorvete ou aguardar o transporte para voltar ao sítio. E, apesar da feira acontecer na rua ao redor da praça, alguns comerciantes usam o espaço da praça para montar suas barracas e vender seus produtos ou serviço (Figura 6 e 7 ). 

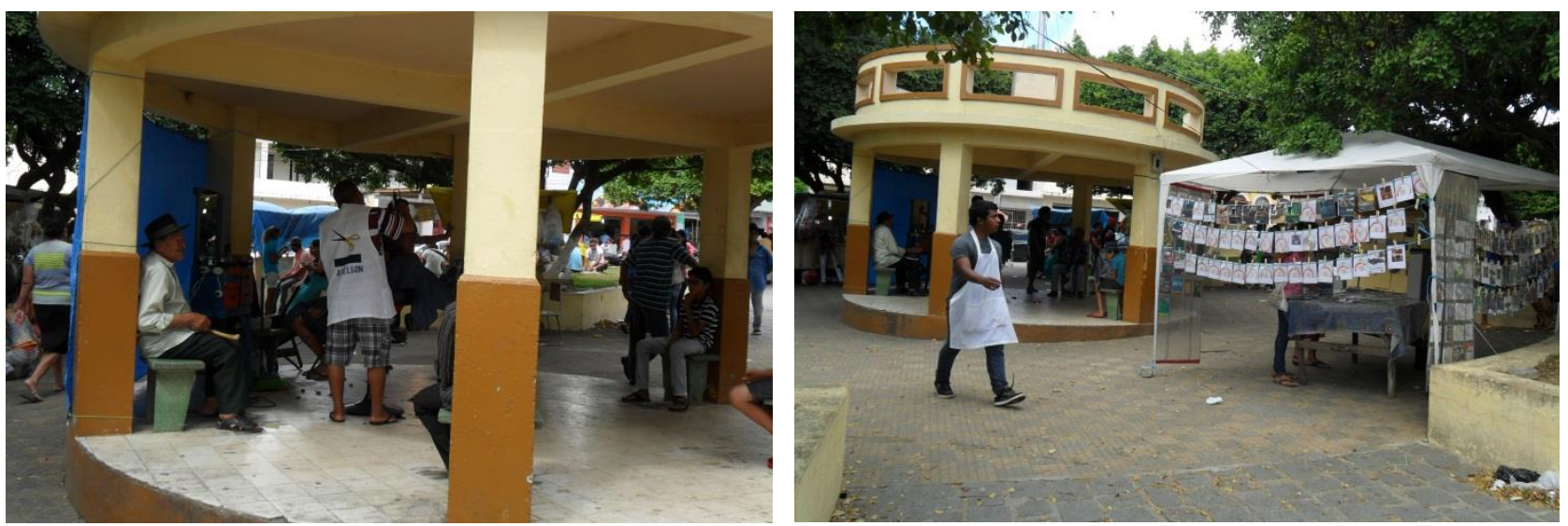

Figuras 6-7: atividades comerciais na praça. Fonte: Chaves 2013.

Diante dessa elevada utilização da praça pelos comerciantes, procurou-se saber como eles se relacionam com o espaço que se apropriam para determinadas atividades econômicas, enfatizando que eles estavam usando um espaço arborizado. Com o objetivo de perceber qual a relação sistêmica que eles apresentam ter com o ambiente urbano com a presença elementos naturais e artificiais.

Para tal objetivo, realizou-se uma entrevista aberta com sete comerciantes, que ofertavam diferentes tipos de produto e serviços. Salientando-se que, no quadro de comerciantes também incluiu-se aqueles que, apenas não usam a praça no dia de sábado, mas também se apropriam dela durante a semana para o desenvolvimento de sua atividade comercial seja bar, sorveteria e barraca de salgadinhos e doces.

O quadro 1, mostra a principal percepção que os comerciantes tem da praça Nossa Senhora da Conceição em relação aos usos ou apropriação que fazem dela nos sábados e a importância da arborização presente na mesma. 


\begin{tabular}{|c|c|c|c|c|c|c|c|}
\hline $\begin{array}{c}\text { Entrevistados } \\
\text { Percepções } \\
\mathbf{t}\end{array}$ & $\begin{array}{c}\text { Usa o } \\
\text { espaço }\end{array}$ & $\begin{array}{c}\text { Usa o } \\
\text { espaço }\end{array}$ & $\begin{array}{c}\text { Usa o } \\
\text { espaço }\end{array}$ & $\begin{array}{c}\text { Apropria } \\
\text { o } \\
\text { espaço }\end{array}$ & $\begin{array}{c}\text { Apropria } \\
\text { o } \\
\text { espaço }\end{array}$ & $\begin{array}{c}\text { Usa o } \\
\text { espaço }\end{array}$ & $\begin{array}{c}\text { Usa o } \\
\text { espaço }\end{array}$ \\
\hline $\begin{array}{c}\text { Referente à } \\
\text { localização }\end{array}$ & Boa & Boa & $\mathbf{x}$ & Boa & Boa & Boa & Boa \\
\hline $\begin{array}{c}\text { Referente à } \\
\text { arborização }\end{array}$ & Sombra & Sombra & $\mathbf{x}$ & Sombra & Sombra & Sombra & Sombra \\
\hline $\begin{array}{c}\text { Referente a } \\
\text { outros } \\
\text { elementos }\end{array}$ & $\mathbf{x}$ & $\mathbf{x}$ & $\mathbf{x}$ & Estética & $\mathbf{x}$ & $\mathbf{x}$ & Estética \\
\hline
\end{tabular}

Quadro 1: percepção que os comerciantes têm em relação a praça e sua arborização. Fonte: Chaves 2013

Logo, pelo quadro 1 salientado, verifica-se que os comerciantes não percebem mais do que três funções ou benefícios da praça. Um dos entrevistados não percebe nem uma importância, diz que a praça é neutra e não contribui para seu negócio. E dois outros, além de se referir à boa localização que a praça possibilita a seu trabalho salientam o papel importante da árvore por causa da sombra. Também citam o fator estético da praça, enfatizando a beleza que ela tem devido à arborização, mas, infelizmente nenhum dos entrevistados refere-se a outros benefícios que são provenientes da arborização.

Em relação ao uso da praça nos domingos, verificou-se ser por grupos de amigos de diferentes idades. Estes se juntam para conversar, tomar sorvete, aproveitar um ambiente sombreado, bem como a área de circulação nos horários antes e após a missa. Especificamente no domingo, o uso pelo processo de apropriação econômica da praça diminui, pois se verifica mais a circulação das pessoas em função do ofício religioso associado a um dia de descanso da semana.

Embora a população não perceba toda vez que, de alguma forma, usam ou se apropriam do espaço da praça, estabelecem uma relação sistêmica com o espaço e os elementos que a constituem. Um grupo de amigos que joga dominó embaixo de uma árvore está a usufruir de um momento de lazer, em um ambiente arborizado, que disponibiliza sombra amenizando as altas temperaturas, protege o solo do impacto das gotas da chuva, contribui para presença da micro fauna nos centros urbanos proporcionando, ainda, a presença de pássaros, lagartas, formigas e outros pequenos 
animais, diminuindo a poluição sonora e do ar entre outros benefícios ao meio ambiente da cidade.

\section{A ARBORIZAÇÃO dA PRAÇA NOSSA SENHORA DA CONCEIÇÃO E SUAS CONTRIBUIÇÕES PARA SUSTENTABILIDADE AMBIENTAL DO MUNICÍPIO}

É notável em qualquer cidade que a presença de um espaço arborizado como uma praça deixa o ambiente mais agradável, principalmente durante as épocas quentes do ano. Porém poucas pessoas ou quase nenhuma, se preocupam em saber qual a importância dessa presença natural, principalmente através da arborização, no meio do espaço tão artificial, como o urbano.

Também é fato que todo habitante da cidade quer um ambiente harmonioso que Ihe permita ter uma vida de qualidade. Que possam disfrutar de áreas verdes para o lazer, do ar limpo para respirar, da sustentabilidade urbana para desenvolver suas necessidades e atividades coletivas e individuais.

Nessa perspectiva, introduz-se a contribuição da arborização da Praça Nossa Senhora da Conceição de Correntes-PE. Salientando-se que a praça é um ambiente de relações sociais, como mostra Silva apud Benini e Martin,

A função da praça não é tanto a circulação, mas a permanência, o lazer e atividades cívico-religiosas. Por esta razão é que em sua área interna se admite edificação institucional, como igreja, fórum, câmaras legislativas, palácios governamentais e semelhantes. Tem a função de embelezamento da cidade, por seus aspectos ornamentais, tanto que sempre foi da tradição construírem-se, nas margens das praças edifícios mais representativos. (SILVA apud BENINI; MARTIN, 2011, p. 69).

Assim, fica evidente que a praça é um ambiente de variadas funcionalidades voltado às inter-relações entre os homes e os elementos constituintes da praça. Sendo que a praça também é classificada como áreas verdes públicas e de uso coletivo que possui alto valor ecológico, cênico e social.

E o que vai caracterizar a praça como uma área verde é a presença da vegetação/arborização (natureza), e são esses elementos naturais que contribuem para a sustentabilidade ambiental do município. Elementos esses que contribuem para a 
sustentabilidade do ambiente envolvendo desde um ambiente harmônico para o lazer, a arborização na cidade é importante sob os aspectos ecológico, histórico, cultural, social, estético e paisagístico, contribuindo para diversos benefícios para cidade e a população.

De acordo com o manual de arborização urbana, e as observações, bem como a percepção que se desenvolveu com a observação in loco, admite-se que os benefícios provenientes da arborização da Praça Nossa Senhora da Conceição contribui para sustentabilidade de Correntes são:

- A manutenção da estabilidade microclimática;

- O conforto térmico associado à umidade do ar e à sombra;

- A melhoria da qualidade do ar;

- A redução da poluição;

- A melhoria da infiltração da água no solo, evitando erosões associadas ao escoamento superficial das águas das chuvas;

- A proteção e direcionamento do vento;

- O abrigo à fauna silvestre, contribuindo para o equilíbrio das cadeias alimentares, diminuindo pragas e agentes vetores de doenças;

- O cotidiano da população, funcionando como elementos referenciais marcantes;

- O embelezamento da cidade proporcionando prazer estético e bem estar psicológico;

- O aumento do valor das propriedades. (MANUAL DE ARBORIZAÇÃO, 2011, p.21).

Assim a praça estudada só oferece beneficio a cidade das Correntes e a seus moradores. Ela é o centro do município e foi a sua volta que a cidade se desenvolveu e cresceu. É um espaço de múltipla funcionalidade e um lugar que a população correntense usufrui com segurança, sem discriminação ou divisão social e apesar de sua pequena apropriação com fim econômico é um espaço livre de construção e área verde acessível a toda população.

\section{CONSIDERAÇÕES FINAIS}


Levando-se em consideração que o presente trabalho é parte de uma pesquisa mais ampla sobre o verde das praças e canteiros centrais da paisagem Agreste do Município Correntes-PE, a Praça Nossa Senhora da Conceição é o principal espaço livre e arborizado do município, apresenta um gama de funcionalidades que engloba seus modos de uso e apropriação, os quais variam de acordo com os dias da semana devido às atividades desenvolvidas na referida cidade.

Assim, com o desenvolvimento da pesquisa na praça em questão chega-se as seguintes considerações: a Praça Nossa Senhora da Conceição apresenta um cenário aconchegante a população de Correntes-PE, que devido a esse fato fazem dela um lugar com múltiplas utilizações para o lazer e bem estar, bem como de apropriações por pequenos comerciantes que usam a localização da praça como ponto estratégico no desenvolvimento do comércio.

A praça é o ponto de maior circulação do município devido ao seu desenvolvimento que ocorreu junto ao comercio da cidade. E sua construção foi devido a necessidade de criar um ambiente mais agradável no local da feira livre, (até nos dias atuais, a feira livre ocorre aos sábados pela manhã em torno da praça e em ruas próximas) e, aos poucos devido a utilização do espaço, se fez necessário construir mais que um ambiente agradável para a feira, mas sim um ambiente que a população pudesse desfrutar a qualquer hora.

Surgiu, então, a Praça Nossa Senhora da Conceição, a qual não representa apenas um espaço livre disponível para as atividades recreativas da população, mas também uma área verde urbana, que contribui para sustentabilidade ambiental do município, devido aos benefícios advindos da arborização. A praça é um sistema aberto, de trocas de energias entre os elementos naturais e os elementos artificias da cidade em uma relação harmônica de contradição.

Porém, apesar dos benefícios que a praça proporciona, a população que a frequenta está lá para desfrutar de um ambiente agradável para o lazer ou finalidade comercial, poucos dos utilizadores ou apropriadores da praça apresentam ter uma relação de valorização aos elementos naturais ali presente. Percebe-se, ainda, que os mesmos não dispõem de conhecimento suficiente acerca dos benefícios que a arborização desempenha para o ambiente urbano. Sendo necessária uma conscientização para a 
população de uma maneira geral, quanto a presença arbórea na praça valorização da mesma do ponto de vista subjetivo e afetivo tornando-se importante, assim, para o bom desenvolvimento do ambiente da cidade e da vida nela.

\section{REFERÊNCIAS}

AMADOR, Maria Betânia Moreira. Sistemismo e sustentabilidade: questão interdisciplinar. São Paulo: Scortecci, 2011.

O pensamento de Edgar Morin e a geografia da complexidade. Revista Científica ANAP Brasil, n. 2, ano 2 - p. 60-76. 2009

BENINI, Sandra Medina; MARTIN, Encarnita Salas. Decifrando as áreas verdes públicas. Revista Formação, n.17, volume 2 - p. 63-80, 2011.

Companhia Energética de Minas Gerais. Manual de arborização. Belo Horizonte: Cemig/Fundação Biodiversitas, 2011. Disponível em: <www,comig.com.br/.../ManualArborização-Cemig-biodiversidade.pd...> acesso em 22/02/2012.

DARDEL, Eric. O homem e a terra: natureza da realidade geográfica. Tradução de Werther Holzer. São Paulo: Perspectiva: 2011.

SANTOS, Milton. A natureza do espaço técnica e tempo. Razão e emoção. 2 ed. São Paulo: Hucittec, 1997.

SANTOS, Silveira Ribeiro. Arborização urbana: considerações. Disponível em <www.aultimaarcadenoe.com.br>. Acesso em 15 jul. 2012.

SÁ CARNEIRO, Ana Rita; MESQUITA, Liana de Barros. Espaços livres de Recife. Recife: prefeitura da cidade do recife/Universidade Federal de Pernambuco, 2000.

SCHUTZER, José Guilerme. Cidade e meio ambiente: a apropriação do relevo no desenho ambiental urbano. São Paulo: Ed. Universidade de São Paulo, 2012.

SERPA, Angelo. O espaço público na cidade contemporânea. São Paulo: Contexto, 2009. 